\title{
Investigasi Air Tanah Pada Endapan Piroklastik dengan Menggunakan Metode Electrical Resistivity Imaging (ERI)
}

\section{(Groundwater Investigation in Pyroclastic Deposits Using the Electrical Resistance Method (ERI))}

\author{
A. Y. Paembonan ${ }^{1)}$,D.R. Febriansanu ${ }^{2)}$, R. E. Sinaga ${ }^{1)}$, F. D. Putra ${ }^{1)}$, V. Rahmanda ${ }^{1)}$ \\ Program Studi Teknik Geofisika, Institut Teknologi Sumatera 1) \\ Program Studi Teknik Geologi, Institut Teknologi Sumatera ${ }^{2)}$
}

Info

Article history:

Received: 21 Juni 2020

Accepted: 28 Juni 2020

Published: 30 Juni 2020

\begin{abstract}
Abstrak.
Penelitian untuk menginvestigasi keberadaan air tanah menggunakan metode Electrical Resistiity Imaging (ERI) dilakukan di kampus Institut Teknologi Sumatera (ITERA), Lampung Selatan yang daerahnya didominasi endapan piroklastik. Penelitian dilaksanakan di laboratorium untuk mengukur nilai resistivitas material secara langsung, dan juga dilakukan pengukuran data lapangan. Pengamatan laboratorium menunjukkan variasi nilai resistivitas untuk tuf pada kondisi kering berkisar 78.39 - $268.78 \Omega \mathrm{m}$, dan nilai resistivitasnya menjadi 15.35 - $45.82 \Omega \mathrm{m}$ ketika tersaturasi, sedangkan nilai resistivitas untuk lempung tufan kering sebesar $93.36-292.48 \Omega \mathrm{m}$ dan pada saat tersaturasi air sebesar $4.56-13.47 \Omega \mathrm{m}$. Pada data lapangan pada lapisan pertama yang didominasi tuf dengan nilai resistivitas sedang sampai tinggi karena materialnya kering, lapisan kedua dan keempat mempunyai resistivitas rendah karena tersaturasi oleh air, dan lapisan ketiga diinterpretasi sebagai lempung tufan dengan nilai resistivitas sedang hingga tinggi. Dari hasil mengindikasikan adanya akuifer pada kedalaman $0-30 \mathrm{~m}$ dan kedalaman di bawah $60 \mathrm{~m}$.
\end{abstract}

\section{Abstract.}

Research has been carried out to investigate the ground water resources using the Electrical Resistivity Imaging (ERI) in the Lampung area, precisely at the ITERA Campus Area in South Lampung, where the area is dominated by pyroclastic deposits. This research was conducted in a laboratory to measure the resistivity value of the material directly and field measurement was also conducted. The laboratory observations show that resistivity variations of dry tuff ranging from $78.39 \Omega m$ to $268.78 \Omega \mathrm{m}$, the resistivity value decreased due to water saturation, $15.35 \Omega \mathrm{m}$ to 45.82 $\Omega m$. The field data show that the first layer is dominated by tuff with medium to high resistivity values, while the second and fourth layers show the low resistivity because it is saturated with water, whereas the third layer is interpreted as a tuff-clay with medium to high resistivity values. From these results there are 2 layers that have a low resistivity value which indicates groundwater zone at a depth of $0-30 \mathrm{~m}$ and at a depth under $60 \mathrm{~m}$.

Aquifer;

ERI; ;

Pyroclastic;

Resistivity

*) e-mail: andri.paembonan @tg.itera.ac.id

\section{PENDAHULUAN}

Air tanah merupakan kebutuhan vital bagi kehidupan makhluk hidup termasuk manusia, terutama di daerah yang sulit mendapatkan aliran air sungai, danau dll. Kondisi ini juga dipengaruhi oleh jumlah populasi penduduk yang semakin meningkat yang menyebabkan kebutuhan air semakin bertambah. Belum lagi ketika musim kemarau tiba, keberadaan air akan semakin sulit terutama untuk air permukaan, sehingga alternatifnya adalah dengan pemanfaatan air tanah. Air tanah adalah reservoir air tawar terbesar kedua dengan kapasitas sekitar 30\% dari semua air tawar yang ada di bumi, dibandingkan dengan reservoir air permukaan yang hanya berjumlah sekitar $0,3 \%$ [1]. Keberadaan air tanah sangat dipengaruhi oleh kemampuan sebuah batuan untuk dapat menyimpan air. Di Indonesia pada 
umumnya, hampir semua wilayahnya terdapat endapan piroklastik. Hal ini dikarenakan Indonesia merupakan negara yang memiliki barisan gunung api aktif yang berada pada hampir semua wilayah. Keberadaan endapan piroklastik ini mempengaruhi keberadaan air tanah [2, 3]

Air tanah sendiri dikontrol oleh beberapa faktor seperti porositas, dan permeabilitas [4]. Air tanah biasanya ditemukan di daerah yang mempunyai porositas tinggi dan permeabel, yang mudah tersaturasi oleh air atau disebut akuifer . Material pada endapan piroklastik umumnya mempunya nilai porositas dan permeabilitas yang bervariasi tergantung pada tergantung pada jenis dan intensitas proses ledakan dan pada mekanisme penempatannya, serta proses perubahan postdeposisi [5] Khusus daerah deposit vulkanik sistem akuifer sendiri cenderung mudah untuk ditemukan yang umumnya terdiri dari batuan seperti pasir, tuf, kerikil ataupun batuan lain yang memiliki porositas dan permeabilitas yang tinggi [2].

Dalam ilmu kebumian, metode geofisika sudah banyak dimanfaatkan untuk mendeteksi keberadaan akuifer. Metode geofisika seperti Electrical Resistiity Imaging (ERI) [6, 7, 8], kombinasi metode Vertical Resistivity Sounding (VES) dan elektromagnetik (EM) [9], dan integrasi metode magnetik, very low frequency electromagnetic (VLF) and geolistrik resistivitas [10], telah berhasil diaplikasikan di berbagai belahan dunia. Selain mendapatkan hasil yang cepat, metode ini juga lebih murah dan mudah untuk diaplikasikan. Metode ERI memanfaatkan sifat kelistrikan batuan berupa nilai resistivitas (Tabel 1) yang berkaitan dengan parameter porositas dan permeabilitas sebuah batuan. Semakin besar nilai porositas dan permeabilitas maka nilai resistivitas akan semakin kecil [11]. Hal ini berkaitan dengan konduksi listrik yang dipengaruhi oleh keberadaan fluida pada pori batuan dan derajat saturasi air serta mineral yang terkandung dalam batuan.

Tabel 1 Resistivitas material [12]

\begin{tabular}{ll}
\hline Jenis material & Resistivitas ( $\mathbf{\Omega m})$ \\
\hline Igneous and Metamorphic & \\
Rocks & $5 \times 103-106$ \\
Granite & $103-106$ \\
Basalt & $6 \times 102-4 \times 107$ \\
Slate & $102-2.5 \times 108$ \\
Marble & $102-2 \times 108$ \\
Quartzite & \\
\hline
\end{tabular}

\begin{tabular}{l}
\hline Sedimentary Rocks \\
Sandstone \\
Shale \\
Limestone
\end{tabular}

$$
\begin{aligned}
& 8-4 \times 103 \\
& 20-2 \times 103 \\
& 50-4 \times 102
\end{aligned}
$$

\begin{tabular}{ll} 
Soils and Water & \\
Clay & $1-100$ \\
Alluvium & $10-800$ \\
Groundwater & $10-100$ \\
Sea water & 0.2 \\
\hline
\end{tabular}

Konduksi listrik di dalam batuan maupun mineral dapat digolongkan menjadi tiga macam, yaitu konduksi secara elektronik, konduksi secara elektrolitik, dan konduksi secara dielektrik. Konduksi secara elektronik terjadi jika batuan atau mineral mempunyai banyak elektron bebas sehingga arus listrik mengalir dengan baik dalam batuan atau mineral oleh elektron-elektron bebas tersebut. Sementara konduksi secara elektrolitik berkaitan dengan konduksi arus listrik yang dibawa oleh ion-ion elektrolit dalam air. Konduksi pada batuan atau mineral bersifat dielektrik terhadap aliran listrik, artinya batuan atau mineral tersebut mempunyai elektron bebas yang relatif sedikit, bahkan tidak ada sama sekali, tetapi karena adanya pengaruh medan listrik dari luar maka elektron dalam bahan berpindah dan berkumpul terpisah dari inti, sehingga terjadi polarisasi [13].

Penelitian ini dilakukan di daerah Lampung, tepatnya pada area Kampus ITERA di Lampung Selatan dengan menggunakan metode ERI. Penelitian sebelumnya dilakukan dalam area kampus ITERA dengan mengkorelasikan antara data electrical logging dan VES memperlihatkan keberadaan air tanah yang berbeda pada setiap lokasi pengukuran dengan kedalaman berkisar antara 80 sampai 125 meter dengan nilai resistivitas $>80 \mathrm{ohm}$ meter [14]. Penelitian ini difokuskan untuk memahami nilai resistivitas pada material piroklastik secara langsung melalui pengukuran laboratorium dan membandingkan dengan data yang diukur di lapangan. Dengan adanya data yang lebih akurat diharapkan dapat digunakan sebagai acuan pada penelitian selanjutnya pada lokasi formasi batuan yang sama.

\section{GEOLOGI DAERAH PENELITIAN}

Dalam proses interpretasi, nilai resistivitas yang didapatkan dari hasil pengolahan data lapangan sangat membutuhkan pemahaman geologi dan informasi geologi yang akurat. Pemahaman geologi yang baik dalam mencocokkan data dan kondisi di lapangan akan sangat membantu dalam interpretasi data geofisika. Lokasi penelitian dapat ditemukan pada Peta Geologi Lembar Tanjung Karang pada Formasi Lampung (Qtl) dengan umur Kuarter yang mendominasi hampir seluruh wilayah pada Lembar Tanjung Karang (Gambar 1). Formasi Lampung umunya tersebar luas di bagian Timur dan Timur Laut dengan ketebalan mencapai 500 yang didominasi oleh batuan riolit-tufan dan vulkanoklastik tufan yang terdiri dari tuf berbatu apung, tuf riolitik, tuf padu tufit, batu lempung tufan dan batu pasir tufan, yang diendapkan di lingkungan terestrial-fluvial air payau dan menindih tak selaras batuanbatuan yang lebih tua [15].

\section{BAHAN DAN METODE}

Uji laboratorium seperti yang terlihat pada Gambar 2, dilakukan menggunakan instrumen geolistrik Naniura di Laboratorium Teknik Geofisika Institut Teknologi Sumatera (ITERA). Adapun bahan dan alat yang digunakan dalam penelitian ini adalah sebagai berikut:

- Sampel berupa tuf (sampel A) dan lempung tufan (sampel B) diambil dari lapangan yang berada di lokasi yang sama dengan pengukuran data lapangan di area kampus Institut Teknologi Sumatera.

- Air yang akan digunakan untuk sampel,

- Medium berupa akuarium,

- Instrumen geolistrik Naniura untuk mengukur nilai potensial dan arus yang diinjeksikan dilengkapi dengan jepit buaya dan Banana Jack serta paku sebagai elektroda.

Pengukuran laboratorium dilakukan dengan menggunakan konfigurasi Wenner dengan jarak elektroda $0.02 \mathrm{~m}, 0.04 \mathrm{~m}$, 


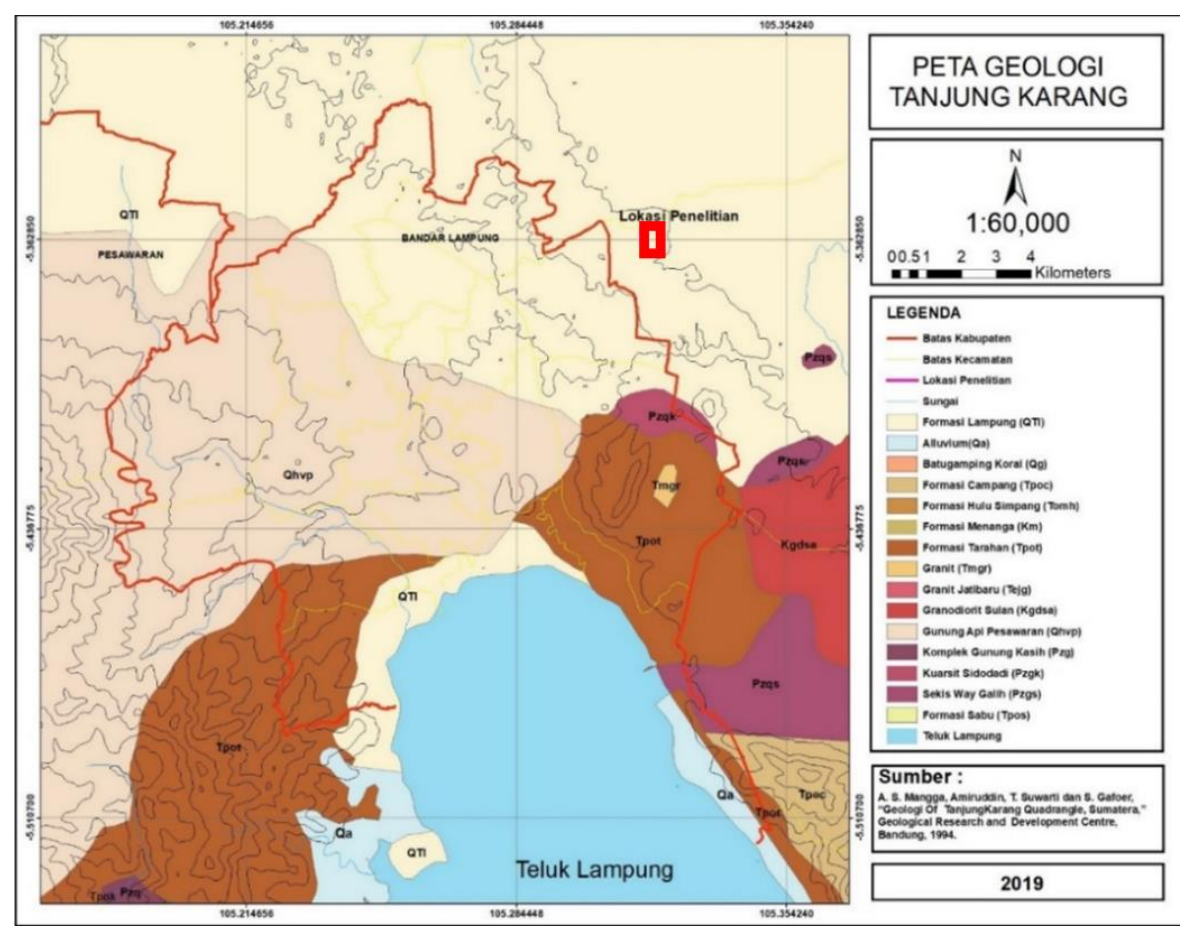

Gambar 1 Peta geologi daerah penelitian (modifikasi dari [15]).

0.06m. Pada uji laboratorium dilakukan pengukuran untuk mengetahui nilai resistivitas masing-masing sampel pada kondisi kering atau sebelum diinfiltrasi dan pada kondisi basah (setelah diinfiltrasi). Data yang diperolah berupa nilai arus yang diinjeksikan (I) dan beda potensial $(\Delta V)$ yang terukur. Nilai resistitas dapat dihitung dangan menggunakan persamaan:

$\rho=K \frac{\Delta V}{I}$

Dimanah K adalah faktor geometri dai konfigurasi Wenner:

$K=2 \pi a$

Dimanah a adalah spasi elektroda dan $\pi$ merupakan konstanta $(\pi=3,14)$. Hasil nilai resistivitas yang diperoleh untuk setiap jarak elektroda kemudian dicari nilai rata-ratanya.

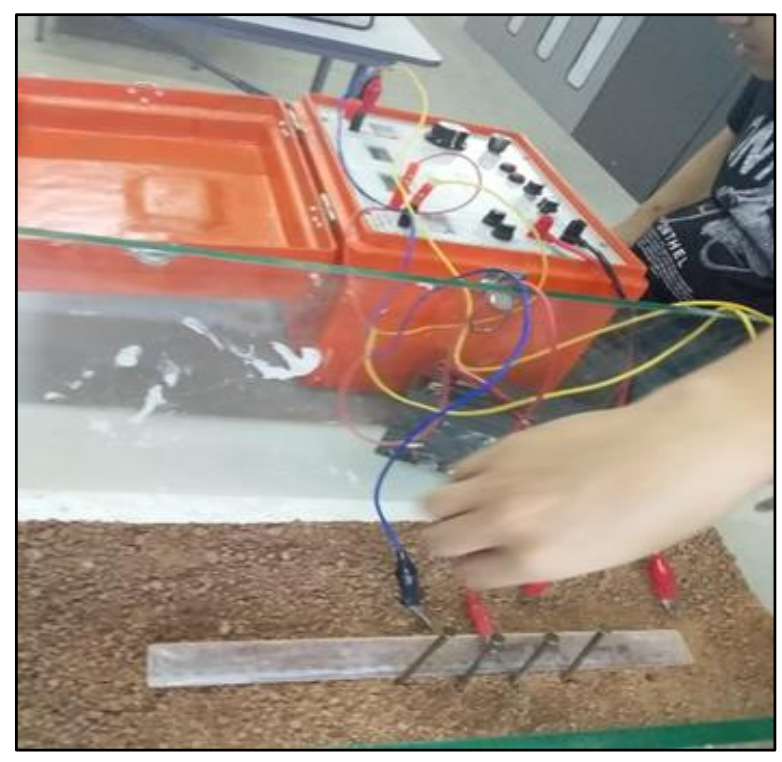

Gambar 2 Proses pengukuran sampel di Laboratorium untuk mengetahui nilai resistivitas pada setiap material.
Akuisisi data lapangan dengan metode ERI menggunakan instrumen ARES. Alat ini merupakan alat multi cannel, menggunakan 48 elektroda yang kemudian dihubungkan dengan kabel multi-core. Pada penelitian ini digunakan jarak spasi elektroda yang 10 meter dengan 2 jenis konfigurasi yang berbeda, Wenner dan Wenner-Sclumberger. Alat ini juga dilengkapi dengan switch-box yang berfungsi untuk pengukuran secara otomatis. Pada instrumen utama, terlebih dahulu diatur parameter yang akan digunakan seperti pada Tabel 2. Selanjutnya untuk memulai pengukuran, terlebih dahulu dilakukan pengecekan untuk memastikan semua komponen terhubung dengan baik. Data dari hasil pengukuran berupa nilai arus (I), beda potensial $(\Delta V)$ dan resistivitas semu, serta parameter geometri akan tersimpan secara otomatis pada memori instrumen. Data yang telah tersimpan kemudian di unduh ke komputer dan selanjutnya dianalisis dan diproses dengan menggunakan perangkat lunak inversi Res2Dinv [12, 16] untuk mendapatkan penampang resistivitas sebenarnya.

Tabel 2 Parameter yang digunakan pada pengukuran geolistrik.

\begin{tabular}{ll}
\hline Parameter & Value setting \\
\hline Konfigurasi elektroda & Wenner-Sclumberger danWenner \\
Jarak spasi antar-elektroda & \\
terkecil & $10 \mathrm{~m}$ \\
Maksimum standar deviasi & 5 \\
Maksimal Stack & 5 \\
Minimal Stack & 3 \\
Voltage & $800 \mathrm{~V}$ \\
\hline
\end{tabular}

\section{HASIL DAN PEMBAHASAN}

Dari hasil perhitungan nilai resistivitas pada uji sampel A dengan spasi elektroda $0,02 \mathrm{~m}$; diperoleh nilai resistivitas ratarata pada kondisi kering sebesar $78.39 \Omega \mathrm{m}$, sedangkan resistivitas pada kondisi basah adalah $15.35 \Omega$ m. Pada spasi elektroda $0,04 \mathrm{~m}$; resistivitas rata-rata pada kondisi kering adalah $174.58 \Omega \mathrm{m}$, dan resistivitas pada kondisi basah adalah $23.62 \Omega \mathrm{m}$. Pada spasi elektroda $0,06 \mathrm{~m}$; nilai resistivitas rata- 
rata pada kondisi kering adalah $268.78 \Omega \mathrm{m}$, dan nilai resistivitas pada kondisi basah adalah $45.82 \Omega \mathrm{m}$. Dari hasil ini terlihat bahwa nilai resistivitas sampel A pada kondisi kering mempunyai nilai resistivitas sedang sampai tinggi, sedangkan pada kondisi basah sampel A mempunyai sifat yang konduktif dengan. Penurunan nilai resistivitas rata pada saat kering dan pada kondisi basah sekitar $80 \%$. ।

Tabel 3 Nilai Resistivitas rata-rata pada sampel tuf (Sampel A) basah dan kering

\begin{tabular}{ccc}
\hline Spasi & $\begin{array}{c}\text { Resistivitas Rata- } \\
\text { rata Sampel Kering } \\
(\mathbf{\Omega m})\end{array}$ & $\begin{array}{c}\text { Resistivitas Rata- } \\
\text { rata Sampel basah } \\
(\mathbf{\Omega m})\end{array}$ \\
\hline $\mathbf{0 . 0 2}$ & 78.39 & 15.35 \\
$\mathbf{0 . 0 4}$ & 174.58 & 23.62 \\
$\mathbf{0 . 0 6}$ & 268.78 & 45.82 \\
\hline
\end{tabular}

Pada sampel B dengan spasi elektroda $0,02 \mathrm{~m}$; nilai resistivitas rata-rata pada kondisi kering adalah $93.36 \Omega \mathrm{m}$, sedangkan nilai resistivitas pada kondisi basah adalah 5.76 $\Omega \mathrm{m}$. Pada jarak elektroda $0,04 \mathrm{~m}$; diperoleh nilai resistivitas rata-rata pada kondisi kering sebesar $194.70 \Omega \mathrm{m}$, dan nilai resistivitas pada kondisi basah adalah $13.471 \Omega$ m. Pada jarak elektroda $0,06 \mathrm{~m}$; diperoleh nilai resistivitas rata-rata pada kondisi kering adalah $292.48 \Omega \mathrm{m}$, dan nilai resistivitas kondisi basah adalah $4.56 \Omega \mathrm{m}$. Pada sampel B dapat dilihat bahwa terjadi penurunan nilai resistivitas rata sebesar $141.55 \Omega \mathrm{m}$. Dari data uji laboratorium yang didapatkan kemudian digunakan untuk melakukan interpretasi terhadap data lapangan. Selain itu, digunakan juga informasi dari penelitian sebelumnya, terutama untuk lapisan yang lebih dalam karna keterbatasan dalam pengambilan sampel.

Penampang resistivitas pada pengukuran lapangan dengan panjang lintasan $480 \mathrm{~m}$ dan menggunakan konfigurasi Sclumberger ditampilkan pada Gambar 3. Dari hasil tersebut terdapat 3 buah lapisan batuan yang berada di lokasi tersebut dan didominasi oleh batuan dengan nilai resistivitas yang bernilai sangat rendah. Pada lapisan paling atas memiliki persebaran nilai resistivitas medium 60-120 $\Omega \mathrm{m}$ dengan ketebalan sekitar 10 meter diinterpretasikan sebagai tuf dalam kondisi kering. Pada lapisan dibawanya memiliki nilai resistivitas rendah yang diinterpretasi sebagai zona akuifer bebas dengan material didominasi tuf. Kondisi ini dikarenakan pada batuan tuf apabila dalam keadaan tersaturasi maka air akan masuk ke dalam ruang pori batuan. Pada lapisan ke-3 terdapat nilai resistivitas yang lebih tinggi yang diduga sebagai lapisan lempung tufan. Nilai resistivitas yang tinggi kemungkinan diakibatkan karena materialnya mempunyai nilai porositas dan permeabilitas yang cenderung rendah.

Tabel 4 Nilai Resistivitas rata-rata pada sampel lempung tufan (Sampel B) basah dan kering

\begin{tabular}{ccc} 
Spasi & $\begin{array}{c}\text { Resistivitas Rata-rata } \\
\text { Sampel Kering }\end{array}$ & $\begin{array}{c}\text { Resistivitas Rata- } \\
\text { rata Sampel basah }\end{array}$ \\
\hline $\mathbf{0 . 0 2}$ & 93.36 & 5.76 \\
$\mathbf{0 . 0 4}$ & 194.70 & 13.47 \\
$\mathbf{0 . 0 6}$ & 292.48 & 4.56 \\
\hline
\end{tabular}

Dari hasil model penampang resistivitas 2D dengan konfigurasi Wenner (Gambar 4) terlihat bahwa hasil yang didapatkan mirip dengan hasil dengan konfigurasi Sclumberger hanya berbeda pada kedalaman. Nilai resistivitas pada setiap lapisan terlihat bervariasi. Kedalaman maksimum yang diperoleh sekitar $80 \mathrm{~m}$. Pada lapisan pertama terdapat lapisan tufa dengan nilai resistivitas medium sampai tinggi yang merupakan tuf kering dengan ketebalan lapisan sebesar 10 meter. Lapisan kedua terdapat material yang sangat konduktif yang diduga sebagai tuf yang tersaturasi air yang diduga sebagai akuifer bebas dengan ketebalan hingga 30 meter. Pada lapisan berikutnya terlihat nilai resistivitas sedang hingga tinggi dengan ketebalan maksimum sekitar 35 meter. Pada lapisan terakhir terlihat nilai resistivitas rendah yang terdapat pada kedalaman lebih dari 60-meter yang diinterpretasikan sebagai lapisan akuifer tertekan.

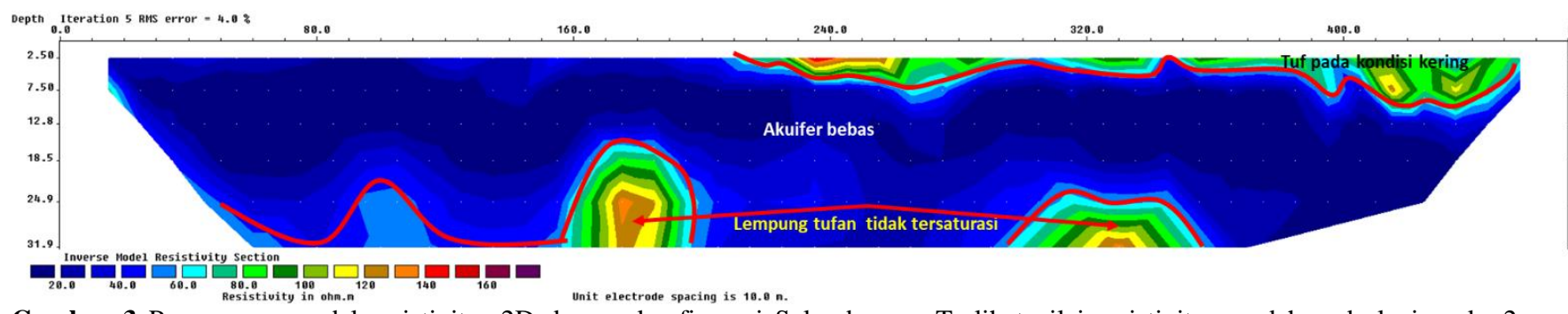

Gambar 3 Penampang model resistivitas 2D dengan konfigurasi Sclumberger. Terlihat nilai resistivitas rendah pada lapisan ke-2 yang diinterpretasikan sebagai zona akuifer bebas.

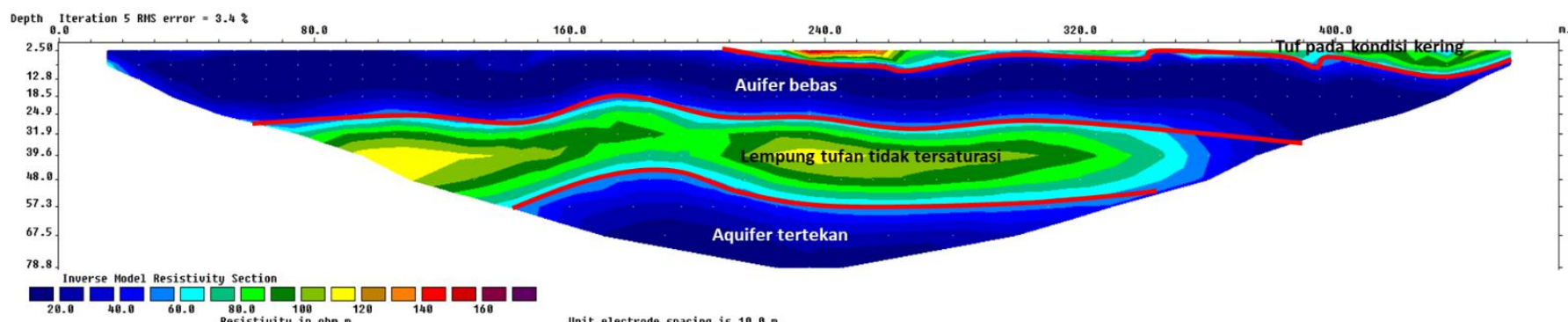

Gambar 4 Penampang model resistivitas 2D dengan konfigurasi Sclumberger. Terlihat 2 zona nilai resistivitas rendah pada lapisan ke-2 dan ke-4 yang diinterpretasikan sebagai zona akuifer. 


\section{KESIMPULAN}

Dari hasil penelitian yang dilakukan di area kampus ITERA didapatkan bahwa pada pengujian laboratorium didapatkan nilai resistivitas untuk tuf pada kondisi kering berkisar antara $78.39 \Omega \mathrm{m}$ sampai $268.78 \Omega \mathrm{m}$, sedangkan pada kondisi basah mempunyai sifat yang konduktif dengan rentang nilai resistivitas mulai dari $15.35 \Omega \mathrm{m}$ sampai $45.82 \Omega \mathrm{m}$. Sedangkan untuk sampel B (Lempung tufan) mempunyai sifat konduktor yang sangat tinggi apabila tersaturasi oleh air dengan nilai resistivitas $4.56-12.47 \Omega \mathrm{m}$, sedangkan apabila dalam kondisi kering memperlihatkan nilai resistivitas yang tinggi, 92.35 $292.48 \Omega \mathrm{m}$. Hal yang sama terlihat pada penelitian di lapangan. Dengan menggunakan dua jenis konfigurasi yang berbeda terlihat bahwa lapisan ke-2 terdapat nilai resistivitas rendah yang diakibatkan karna adanya air tanah pada lapisan tuf dan lempung-tufan. Pada lapisan ini diinterpretasi sebagai lapisan akuifer bebas dan selanjutnya pada lapisan ke-4 ditemukan zona konduktor yang diduga sebagai akuifer tertekan.

\section{DAFTAR PUSTAKA}

[1] I. A. Shiklomanov, "Appraisal and assessment of world water resources.," Water International, pp. 11-32, 2000.

[2] M. Aubert, G. Camus dan C. Fournie, "Resistivity and Magnetic Surveys in Groundwater Prospecting in Volcanic Areas-Case History Maar of Beaunit, Puy De Dome, France*," Geophysical Prospecting, p. 554-563, 1984.

[3] S. Hurwitz, "Groundwater flow, heat transport, and water table position within volcanic edifices: Implications for volcanic processes in the Cascade Range.," Journal of Geophysical Research, 2003.

[4] T. Shao, R. Wang, Z. Xu, P. Wei, J. Zhao, J. Niu dan D. Song, "Permeability and Groundwater Enrichment Characteristics of the Loess-Paleosol Sequence in the Southern Chinese Loess Plateau," Water, pp. 1-16, 2020.

[5] A. Corazza, G. Giordano dan D. de Rita, "Hydrogeology of the, city of Rome," dalam Tuffs : their poperties, uses, drology and resources, Colorado, The Geological Society of America, Inc. , 2006 , p. 131.

[6] A. O. Fajana, "Groundwater aquifer potential using electrical resistivity method and porosity calculation: a case study," NRIAG Journal of Astronomy and Geophysics , pp. 168-175, 2019.

[7] J. E. Amadi, "Application of Electrical Resistivity Method in Groundwater Exploration," SSRN, 2019.

[8] M. Briški, A. Stroj, I. Kosovi'c dan S. Borovi'c, "Characterization of Aquifers in Metamorphic Rocks by Combined Use of Electrical Resistivity Tomography and Monitoring of Spring Hydrodynamics," geosciences, pp. 1-18, 2020.

[9] J. Seidu, A. Ewusi dan J. S. Y. Kuma, "Combined Electrical Resistivity Imaging and Electromagnetic Survey for Groundwater Studies in the Tarkwa Mining Area, Ghana," Ghana Mining Journal, pp. 29 - 41, 2019.

[10] M. A. Olorunniwo dan M. O. Olorunfemi, "Geophysical investigations for groundwater in Precambrian terrains: a case history from Ikare, southwestern Nigeria.," Journal of African Earth Sciences, p. 787-796, 1983.

[11] D. Huntley, "Relations Between Permeability and Electrical Resistivity in Granular Aquifers," Ground Water, pp. 466-478, 1986.

[12] M. H. Loke, Electrical imaging surveys for environmental and engineering studies, 2001.

[13] W. Telford, L. Geldart, R. Sheriff dan D. Keys, AppliedGeophysics, Cambridge: Cambridge University Press, 1982.

[14] Rizka dan S. Satiawan, "Investigasi Lapisan Akuifer Berdasarkan Data Vertical Electrical," Bulletin of Scientific Contribution: GEOLOGY, pp. 91-100, 2019.

[15] S. A. Mangga, Amirudin, T. Suwarti, S. Gafoer dan Sidarto, Peta Geologi Lembar Tanjungkarang, Sumatera, Bandung: Pusat Penelitian dan Pengembangan Geologi, 1993.

[16] M. H. Loke, Tutorial : 2-D and 3-D electrical imaging surveys, 2004. 